\title{
The role of melatonin in modulating parasite infections
}

\author{
Aline do Carmo França-Botelho* \\ Centro Universitario do Planalto de Araxa, Av Minister Olavo Drummond, Brazil
}

Melatonin (N-acetyl-5-methoxytryptamine) is a circadian hormone produced in vertebrates by the pineal gland and other organs, a tryptophan-derived neurohormone participates in various biological functions [1,2]. Among other properties, numerous in vitro or in vivo studies have reported its therapeutic potential against many pathogens. In this concern, melatonin was found to be effective against many parasites such as Plasmodium, Toxoplasma gondii, and Trypansoma cruzi, via various mechanisms such as modulation of calcium level and/ or host immune system [1].

There is evidence influence immune cells leading to modulation of the proliferative response of stimulated lymphocytes as well as cytokine production. Due to the antioxidant and immunomodulatory effects of melatonin, it is suggested that this molecule could be a therapeutic alternative agent to fight bacterial, viral, and parasitic infections, by a several mechanisms. In toxoplasmosis, African trypanosomiasis and Chagas' disease, melatonin enhances host's immune response against the parasite via regulating the secretion of inflammatory mediators. In cases of leishmaniasis, melatonin arrests parasite replication accompanied by releasing mitochondrial $\mathrm{Ca} 2+$ into the cytosol, increasing the level of mitochondrial nitrites and reducing superoxide dismutase (SOD) activity. In another protozoosis, the malaria, melatonin synchronizes the Plasmodium cell cycle via modulating cAMP-PKA and IP3-Ca2+ pathways. Thus the melatonin may be considered a novel approach for treatment of malarial infection [2].

In this context, the therapeutic potential of melatonin in blood protozoan infections is evident. However, considering intestinal parasites, helminths and also protozooses, reports are rare. Intestinal parasites are known to cause anemia, poor physical growth, poor intellectual development, and impaired cognitive function. As a parasitic infection of the gastrointestinal tract affects detrimental effects on host tissues, including major functional interferences, it is relevant for the use of new substances with therapeutic potential for these diseases. In schistosomiasis, the oxidative process that occurs at the site of inflammation has destructive effects on tissues, indicating that free radicals are central components of the disease. One study evaluated melatonin as an immunomodulator of schistosomiasisrelated histopathological changes, showing that the antioxidant action of melatonin is highly protective when administered after Schistosoma mansoni infection and is able to reduce damage such as granuloma formation in the liver [3]. In a model of schistosomiasis in hamsters, melatonin increases the efficacy of cercarial and soluble worm antigens in inducing protective immunity against infection, suggesting possible applications in a vaccination program [4].

One study aimed to evaluate the influence of exogenous melatonin on experimental amoebic infections and its effects on in vitro amoebaleukocyte interactions. This study evaluated the action of melatonin on Entamoeba histolytica, in vivo and in vitro. The results indicated a significant reduction in the areas of amoebic necrosis in response to melatonin treatment. In the animals used, as the areas of necrosis are often associated with large amounts of mainly mononuclear inflammatory infiltrate, thereby containing the infection and reducing the size of liver abscesse [5].

In giardiasis, serum melatonin levels are elevated in these patients; this suggests a positive correlation between the level of melatonin and phagocytic activity in infected patients, possibly related to melatonin's immunomodulatory effect [2]. The study in vitro showed que phagocytes exhibited higher rates of Giardia lamblia elimination when treated with melatonin. In the group of older mothers, colostrum MN phagocytes treated with melatonina obtained a higher microbicidal index for G. lamblia [6].

The definition of the safest and most effective use of melatonin for the different parasitic diseases mentioned is something that deserves further investigation, in vitro and in vivo. On the other hand, the results are encouraging and it is noteworthy that there are also natural ways to increase melatonin levels in the organism. Melatonin was after discovered also in plants, named phytomelatonin. These substances have a positive effect during aging and in pathological conditions too. In particular, it is important to underline that the amount of melatonin produced by pineal gland in human decreases during lifetime and its reduction in blood could be related to pathological conditions in which mitochondria and oxidative stress play a pivotal role. Moreover, it has been indicated that melatonin/phytomelatonin containing foods may provide dietary melatonin, so their ingestion through balanced diets could be sufficient to confer health benefits [7]. Among them, melatonin was identified in plants, medical herbs and many foods, like meat, milk, rice, tomato, banana, potato and in several beverages, that is beer, pomegranate juice and red wine [8].

The prospect of therapeutic use of melatonin in parasitic infections is promising and prompts further investigation, especially in the search for understanding the mechanisms of action and definition of safe and effective doses. In addition, many parasites have not yet been the focus of studies, and perhaps the benefits are wider than currently known.

\section{References}

1. Elmahallawy EK, Luque JO, Aloweidi AS, Gutiérrez-Fernández J, Sampedro-Martínez A, et al. (2015) Potential Relevance of Melatonin Against Some Infectious Agents: A Review and Assessment of Recent Research. Curr Med Chem 22: 3848-3861. [Crossref]

2. Daryani A, Montazeri M, Pagheh AS, Sharif M, et al. (2018) The potential use of melatonin to treat protozoan parasitic infections: A review. Biomed Pharmacother 97: 948-957. [Crossref]

*Correspondence to: Aline do Carmo França-Botelho, Centro Universitário do Planalto de Araxa, Av Minister Olavo Drummond, 38180-084, Araxa, Minas Gerais, Brazil, E-mail: alinecfb@terra.com.br

Received: December 11, 2019; Accepted: January 20, 2020; Published: January 24,2020 
3. El-Sokkary GH, Omar HM, Hassanein AF, Cuzzocrea S, Reiter RJ (2002) Melatonin reduces oxidative damage and increases survival of mice infected with Schistosoma mansoni. Free Rad Biol Med 32: 319-332. [Crossref]

4. Soliman MF, El Shenawy NS, El Arabi SE (2008) Schistosoma mansoni: melatonin enhances efficacy of cercarial and soluble worm antigens in the induction of protective immunity against infection in the hamster. Exp Parasitol 119: 291-295. [Crossref]

5. França-Botelho AC, França JL, Oliveira FMS, França EL, Honório-França AC, et al. (2011) Melatonin reduces the severity of experimental amoebiasis. Parasit Vectors 4 e62. [Crossref]
6. Pereira QLC, Hara CCP, Fernandes RTS, Fagundes DLG, et al. (2018) Human colostrum action against Giardia lamblia infection influenced by hormones and advanced maternal age. Parasitol Res 117: 1783-1791. [Crossref]

7. Bonomini F, Favero G, Rodella LF, Moghadasian MH, Rezzani R (2018) Melatonin Modulation of Sirtuin-1 Attenuates Liver Injury in a Hypercholesterolemic Mouse Model. BioMed Res Int 2018: 7968452. [Crossref]

8. Feng X, Wang M, Zhao Y, Han P, Dai Y (2014) Melatonin from different fruit sources, functional sources and analytical methods. Trends Food Sci Technol 37: 21-31.

Copyright: $\odot 2020$ França-Botelho AC. This is an open-access article distributed under the terms of the Creative Commons Attribution License, which permits unrestricted use, distribution, and reproduction in any medium, provided the original author and source are credited. 